\title{
ARE ALL MY VOLUNTEERS HERE TO HELP OUT? CLUSTERING EVENT VOLUNTEERS BY THEIR MOTIVATIONS
}

\author{
LEONIE LOCKSTONE-BINNEY,* KIRSTEN HOLMES,† KAREN SMITH, $\ddagger$ \\ TOM BAUM,§ AND CHRISTINE STORER \\ *William Angliss Institute, Melbourne, Australia \\ †School of Marketing, Curtin University, Perth, Australia \\ $\ddagger$ School of Management, Victoria University of Wellington, Wellington, New Zealand \\ $\S$ Department of Human Resource Management, University of Strathclyde, Glasgow, Scotland \\ ๆCurtin Business School, Curtin University, Perth, Australia
}

\begin{abstract}
Posed as a question that an event organizer might contemplate in terms of how best to attract and retain event volunteers, this study adds to the event volunteering literature by cluster analyzing volunteers sampled at four sports events using items from the Special Event Volunteer Motivation Scale (SEVMS). The 28 items were first subjected to Exploratory Factor Analysis resulting in four factors (Solidary, Purposive, External Traditions/Commitments, and Spare Time), followed by a two-step clustering procedure and a series of post hoc tests to describe and validate the clusters. As a result of this procedure, three distinct clusters were formed: the Altruists, Socials, and Indifferents. The Altruists and Socials were primarily driven by two distinct internal factors, which respectively represented the Purposive and Solidary factors. The Indifferents appeared to be pushed into volunteering by external forces, rather than intrinsic motivations. Validation revealed that the Indifferents were significantly less satisfied with their volunteer experience than the other two clusters and were also less likely to volunteer in the future. Across the four events sampled, there were distinct patterns of cluster representation, with one event in particular substantially overrepresented by the more negatively inclined Indifferents. The management and research implications of these findings are discussed.
\end{abstract}

Key words: Volunteers; Motivation; Cluster analysis; Sports events

Introduction

Volunteers are integral to the operation and success of many events that vary in terms of scale and scope, ranging from community driven through to mega-sporting events (Holmes \& Smith, 2009). Volunteers undertake a variety of roles, some of which may entail major responsibilities, such as planning and organizing the event, through to helping out on the day. Whatever the role undertaken 
by the volunteer, it is essential for event organizers to understand what motivates volunteers to become involved and this has been a dominant theme in the event volunteering literature.

The focus on motivations has resulted in the development and refinement of a number of scales or "lists" of reasons for event volunteering. The Special Event Volunteer Motivation Scale (SEVMS) (Farrell, Johnston, \& Twynam, 1998) is the most widely tested of these scales. It has been applied by Farrell and colleagues to single events: a women's curling championship (Farrell et al., 1998), a scout jamboree (Johnston, Twynam, \& Farrell, 1999), and a world junior curling event (Twynam, Farrell, \& Johnston, 2002). It has subsequently been tested by other researchers, including Khoo and Engelhorn (2007) at the Malaysian Paralympiad, Reeser, Berg, Rhea, and Willick (2005) at the 2002 Salt Lake City Winter Olympic and Paralympic Games, Grammatikopoulos, Koustelios, and Tsigilis (2006) at YMCA children's summer camps, and an adaptation used by Dickson, Benson, Blackman, and Terwiel (2013) to assess volunteer motives at the 2010 Vancouver Winter Olympic and Paralympic Games. Much of this body of work focuses on conducting either Exploratory or Confirmatory Factor Analysis to explore the latent dimensions of the SEVMS scale, followed by descriptive profiling of volunteers relative to these dimensions.

To the authors' knowledge, research effort has not extended to using the SEVMS to cluster volunteers into heterogeneous groups based on their motivations (i.e., volunteers that are homogenous within the same cluster but significantly different from those grouped in other discrete clusters). This study seeks to address this gap. Such clusters could usefully inform the design of tailored recruitment solutions and retention policies based on the distinct motivational profiles of grouped volunteers, thereby maximizing appeals by event organizers to potential recruits and attracting volunteers whose motives can be satisfied with a view to retaining them for future events. The current examination follows from two recent studies by Treuren (2014) and Alexander, Kim, and Kim (2015), which have demonstrated the application of cluster analysis in respect of event volunteerism research.

Treuren (2014) generated six distinct volunteer clusters based on a motivational scale developed by the researcher (Treuren, 2009). In noting the study's limitations, Treuren (2014) highlights that future research should adopt a "broader and comparative framework for analysis" and that "comparability would be enabled by the use of a consistent, broad scale" (p. 67). The Volunteer Functions Inventory (VFI) (Clary et al., 1998) is cited as an example of such a scale. The VFI tests six major functions of volunteering (Values-concern for others, Understanding-learning and using skills, Social-developing social connections, Careercareer related benefits, Protective-defense of self-image, and Enhancement_enabling personal growth). It has been applied widely in the broader volunteering literature (Allison, Okun, \& Dutridge, 2002; Brayley et al., 2014; Finkelstein, 2008; Lai, Ren, Wu, \& Hung, 2013; Okun, Barr, \& Herzog, 1998; Okun \& Schultz, 2003) but not extensively to the events literature to date. Alexander et al.'s (2015) study answers Treuren's call in part adding an Olympic function factor to the six existing functions of the VFI, as input into segmenting London 2012 volunteers into three distinct groups. Critically, the 21 items tested in the study and the content of the resulting factors appear to bear little resemblance to the 30 -item VFI scale, with 15 items developed specifically for the study, calling into question this particular claim. Indeed, without acknowledgement several items appear to mirror the SEVMS, the focus of the current study.

In advancing the literature, it is proposed that a more robust contribution could be made by recognizing that the motives of event volunteers may be different from those of volunteers in more generic settings (Bang, Alexandris, \& Ross, 2009), while accounting for the need to apply a broader, replicable scale as the basis for clustering event volunteers on their motivations. As such, it appears reasonable that the SEVMS, much tested in relation to a variety of special and sports event settings and based on Cnaan and Goldberg-Glen's (1991) generic volunteer motivation scale, may make a worthwhile contribution in this respect.

A further contribution of the current study is its examination of volunteer cluster profiles across four events, with a view to discerning if certain events are more or less likely to attract certain types of volunteer groupings, distinctions that by design could not be revealed if the dominant approach in 
the literature to single-site studies were applied. Strigas and Jackson (2003) called for event volunteering motivational research to encompass different sport and recreation settings, different countries and cultures, and different types and scales of sporting events. There are a small number of studies that take a comparative or cross-case approach, comparing volunteering at different sporting events (Cuskelly, Auld, Harrington, \& Coleman, 2004; Kemp, 2002), cultural festivals (Smith \& Lockstone, 2009), or across a mix of event types (e.g., Monga, 2006). Treuren's (2014) study added to the multievent literature in surveying volunteers across five events. Unlike Treuren's study for which the data were collected in 2001, cognizant of newer, emerging models of event volunteering such as outsourcing (Lockstone-Binney, Smith, Holmes, \& Baum, 2015), the current study relies on recently collected data to inform its findings.

To frame the study, the literature on event volunteer motivations and volunteer segmentation (clustering) are discussed. Next, the methods used in this study are detailed, and finally, the results and implications are presented.

\section{Literature Review}

\section{Event Volunteer Motivation}

Volunteer motivation in general is a long held topic of interest that has attracted substantial research attention and seminal contributions (e.g., Caldwell \& Andereck, 1994; Clary et al., 1998; Cnaan \& Goldberg-Glen, 1991; Omoto \& Snyder, 1995; Penner \& Finkelstein, 1998). Event volunteering represents a form of episodic volunteering, a more recent pattern of volunteering, moving away from the traditional model of ongoing and sustained involvements. With the terminology "episodic volunteering" coined nearly 25 years ago by Macduff (1991) to refer to one-off volunteering assignments, which offer a flexible relationship with an organization, the concept is hardly new. The phenomenon has become increasingly popular (Grimm, Dietz, Foster-Bey, Reingold, \& Nesbit, 2006; Rochester, Ellis Paine, \& Howlett, 2009) as demographic trends increase, leisure choices, and work-life balance issues affect the time people can commit to volunteering (Australian Government Department of the Prime Minister and Cabinet, 2011; Australian Government Productivity Commission, 2010; Gaskin, 2003; Lockstone, Smith, \& Baum, 2010; Merrill, 2006).

Distinct from more traditional ongoing forms of volunteering, a number of event volunteering motivational scales have developed, contextualized to increasingly greater degrees, to assess motivations relative to specialized event settings. Examples of this specificity include the Olympic Volunteer Motivation Scale (OVMS) (Giannoulakis, Wang, \& Gray, 2008) and the Volunteer Motivations Scale for International Sporting Events (VMS-ISE) (Bang et al., 2009; Bang \& Ross, 2009; Bang, Won, \& Kim, 2009). As noted in the introduction to this study, the SEVMS remains the most recognized event volunteering motivational scale, perhaps in part because it was one of the first attempts to formalize testing of volunteer motives in episodic event settings, representing what Treuren (2009) called "a second generation of event specific scales,” (p. 692) based on Cnaan and Goldberg-Glen's (1991) study.

The 28-item SEVMS scale has generally identified four motivational factors (Farrell et al., 1998). This is contrary to Cnaan and Goldberg-Glen's (1991) original testing on volunteers from human service agencies (including nursing homes and aged-care programs), which yielded a unidimensional scale. This incongruity may explain why Farrell et al. (1998) subsequently interpreted their four-factor solution in part relative to Caldwell and Andereck's (1994) three-factor model (Purposive, Solidary, and Material) of volunteer motivation. The Purposive (contribution to the community and event, linked to altruism) and Solidary factors (social contact, interpersonal relationships, networking, and group status) of the SEVMS, adopting Caldwell and Andereck's terminology, are similar to motives associated with ongoing forms of volunteering (Clary et al., 1998; Penner \& Finkelstein, 1998). The two additional motivational factors identified are more specific to the event context: External Traditions (external obligations linked to extrinsic motivations) and Commitments (fulfilling obligations to the event and/or community). These last two factors merged into one in Johnston et al.'s (1999) later study. Grammatikopoulos et al. (2006) do highlight that the developers' attempts at replicating the SEVMS (Farrell et al., 1998; Johnston et al., 1999) 
have shown that its factor structure is not constant, which they link to the different event settings.

The findings from the SEVMS studies have generally been supported by subsequent studies using other scale instruments. Monga (2006) examined the motivations of volunteers across five different event types: sports events, a community parade, a cultural festival, and an agricultural show. She found that the volunteers' motivations were similar across all five events, which suggests that it is the episodic nature of event volunteering that is a key factor in attracting volunteers. Strigas and Jackson's (2003) study, which like the SEVMS used elements of Cnaan and Goldberg-Glen's (1991) scale, together with Clary et al.'s (1998) VFI, found five motivational factors associated with volunteering at a marathon event. The authors note similarities in their "Egoistic" (need for social interaction and self-actualization) and "External” (volunteering for family or other external reasons) factors compared to the SEVMS's counterpart "Solidary" and "External Traditions" dimensions. Monga (2006) comments that the unique nature of special events means "a more complicated set of explanatory variables than those applicable to more typical volunteering” (p. 51) are likely to come into play, beyond the two- and three-dimensional models of volunteer motivation that dominate the wider volunteering literature.

Although these studies have focused on defining and measuring the latent dimensions of volunteer motivation per se, researchers have also sought to identify patterns of volunteer motivation in relation to other explanatory variables. These studies include comparing the motivations of event volunteers with their sociodemographic profiles (Kemp, 2002; Pauline \& Pauline, 2009), the roles they undertake (Saleh \& Wood, 1998), whether someone is a first time or repeat volunteer (Coyne \& Coyne, 2001; Wollebaek, Skirstad, \& Hanstad, 2014), and the training they receive (Costa, Chalip, Green, \& Simes, 2006). Given the dependence of events on volunteers, a number of studies have also sought to identify whether volunteer motivation can predict volunteer retention (Coyne \& Coyne, 2001; Cuskelly et al., 2004; MacLean \& Hamm, 2007). Extending this work, surprisingly only recently have researchers (Alexander et al., 2015; Treuren, 2014) sought to cluster event volunteers into heterogeneous volunteer groupings, akin to market segments (Cravens \& Piercy, 2006; Palmer \& Millier, 2004), using distance measures to find distinctive cohorts that have meaningful and different relationships between important variables. The following section will provide a brief overview of the limited volunteer segmentation studies, so as to locate the contribution of the current study relative to the extant literature.

\section{Volunteer Segmentation}

The limited studies that have sought to segment or cluster volunteers into heterogeneous groups have done so in recognition of the potential benefits of this practice for promoting tailored approaches to volunteer recruitment and retention, particularly in light of not-for-profit organizations needing to compete for scarce volunteer labor (Dolnicar \& Randle, 2007a; Randle \& Dolnicar, 2009).

Studies have sought to segment volunteers on the basis of number of hours volunteered (Randle \& Dolnicar, 2009), the type of organization volunteered for (Dolnicar \& Randle, 2007a), motivations for volunteering (Dolnicar \& Randle, 2007b), attitudes (to the organization: environment, demands, and commitment), and volunteer motivations (Hustinx \& Lammertyn, 2004) and values among other determinant variables (Wymer, 1997; Wymer \& Starnes, 1999). These studies have generally supported the merits of segmentation for discerning discriminant groups of volunteers.

Treuren's (2014) study provides support for the clustering of event volunteers based on their motivations. In finding six distinct groupings, the motives and associated volunteering behaviors of these clusters vary from the Instrumentalists, motivated to volunteer by tangible rewards (e.g., free tickets), with shorter volunteering careers and lower satisfaction levels, to the Very Keen Enthusiastic, extremely motivated volunteers scoring highest four of the six motives used to cluster the sample. Overall, the clusters differed in terms of volunteer tenure, satisfaction, and other volunteering outcomes. Treuren's study (2014) employs a data-driven segmentation approach, which Dolnicar and Randle (2007b) suggest is superior to traditional "common sense" or a priori approaches that represent "the researcher's 'guess' as to what might discriminate volunteers from other groups” (p. 140). Each of Treuren's six 
clusters are separately described and then intuitively (and with little explanation) reclassified by the researcher into three groups, the Enthusiasts, Conscripts, and Instrumentalists, seemly downplaying the merits of the data driven approach.

Likewise using a data-driven approach, Alexander et al. (2015) factor clustered their motivational scale to produce a three-cluster preferred solution. Labeling the London 2012 volunteer clusters the Obligated, Enthusiasts, and Semienthusiasts, there are similarities between these clusters and those determined in Treuren's study, which at face value may indicate that despite the vastly different event settings of the studies (a mega-event vs. several smaller-scale community events) there are common volunteer types attracted to event volunteering. The largest cluster discerned by Alexander et al.'s study was the Obligated group, which, mirroring the similarly labeled volunteer cluster in Treuren's study, were not very interested in the event itself and in the case of Alexander et al.'s findings, were the cluster with the lowest satisfaction and future intentions to volunteer. The predominance of the Obligated cluster is surprising as Alexander et al. (2015) acknowledge, particularly given mega-event volunteer programs such as those associated with the Olympic Games are often massively oversubscribed (Holmes \& Smith, 2009). Furthermore, the lower intention levels of this cohort, calls into question the often much lauded legacy of increased volunteer participation (International Olympic Committee, 2012) purported to be associated with these high profile, global events.

The current examination extends these studies by fully adopting a data-driven approach to determine if it is possible to segment volunteers sampled from across four events using the widely replicated SEVMS motivational items. The methods employed in advance of this aim are discussed in the next section.

\section{Methods}

This article uses data from a growing comparative, cross-national study of event volunteers - the Event Volunteer Evaluation project (EVE) (LockstoneBinney, Holmes, Baum, \& Smith, 2014). The aim of the overall study is to build a core data set, which over time will facilitate studies of volunteer motivation and satisfaction across a series of events (varying by type, scale, location, and frequency). The four events sampled in the current research include three hosted in Western Australia and one hosted in New Zealand. The Western Australian events included: an annual equestrian multiday event run by Equestrian WA, which took place in August 2011 and featured dressage, cross-country, and show jumping; the International Sailing Federation (ISAF) World Championships, a globally roaming 2-week sailing competition held every 4 years, which as a one-off was held in Perth across a number of venues in 2011; and the Avon Descent, which is an annual 2-day kayak and powerboat race held in August (the data were collected at the 2012 event). The New Zealand event was the IRB Rugby Sevens, a 2-day professional sporting event held annually in Wellington in February, which attracts 35,000 attendees, for which volunteers undertake a number of roles including accreditation, team liaison, and act as runners. These four events were selected as volunteers are involved in similar activities across all four and the researchers were able to negotiate access to survey their volunteer populations.

Additionally, the four events employed a mix of traditional and newer event volunteer management models. As background, the ISAF World Championships and Sevens employed the dominant program management model, for which volunteers are recruited and assigned to roles that meet the needs of the program, rather than attempting to meet the needs of the volunteer (Meijs \& Hoogstad, 2001). This is the model used by most mega and major events and seeks to replicate the Human Resource Management practices used for paid staff with a volunteer workforce (Cuskelly, Hoye, \& Auld, 2006). Third parties, including a mix of voluntary associations as well as local police groups, supplied volunteers for specific roles to the Avon Descent, a newer management model identified as outsourcing by Smith and Lockstone (2009). Finally, the Equine WA event used the emergent Bring Your Own (BYO) volunteer model (Lockstone-Binney et al., 2015), which required that all competitors provide a volunteer (called a "helper") to assist on the day. Although there is a lack of research examining alternative models of event volunteer programs, and no studies linking management models with volunteer motivation, it should be noted that it is beyond the scope and design of this study to explicitly test for these linkages. 
The EVE project uses a standard questionnaire instrument, which has been developed from previous studies of event volunteers. Section A of the survey instrument asks about the volunteer's role at the event; Section B asks about motivation using the SEVMS items; Section C asks about satisfaction with their experience; Section D asks about previous experience of volunteering and future intentions; and Section E asks a number of sociodemographic questions. The SEVMS scale items (Farrell et al., 1998) were assessed using a 7-point Likert scale $(1=$ not at all important to me to $7=$ extremely important to me). Satisfaction was measured using a six-item job satisfaction scale, a shortened version of Brayfield and Rothe's (1951) scale, which has demonstrated high levels of reliability and validity (Agho, Price, \& Mueller, 1992; Iverson, 1996; Price \& Mueller, 1986) and has also been factor analyzed and found to represent a unidimensional factor of overall job satisfaction (Price \& Mueller, 1986). Some minor modifications were made to the scale items to account for the instrument developed in the paid work domain being adapted for use with volunteers (e.g., altering the wording of "job" to "volunteer role").

The questionnaire was administered dependent on the best fit for the event under study. This was face-to-face by trained interviewers at the Equine WA event and the ISAF World Championships, and postal administration for the Avon Descent volunteers. In the case of ISAF, given the bulk of volunteering took place on the water, volunteers could only be approached before or after their shifts. The nature of the Avon Descent, with volunteers spread out over a distance of $124 \mathrm{~km}$ on the two event days meant that it was not possible to collect questionnaires using the face-to-face method. At the Sevens event in 2012, paper copies of the survey were distributed to the 230 volunteers involved in operational event roles. In total, 440 usable surveys were collected, 60 from the Equine WA event, 207 from the ISAF World Championships, 71 from the Avon Descent, and 102 from the Sevens.

The data were analyzed using IBM SPSS v.22. Acknowledging the much larger returned sample from ISAF volunteers and the potential for an eventbased bias in the cluster and post hoc analyses, the ISAF cases were randomized and reduced to achieve a comparable number to that of the Sevens event.
The resultant dataset therefore had a total of 335 cases, including only 102 randomly selected cases sourced from the ISAF World Championships.

An Exploratory Factor Analysis (EFA) was conducted on the SEVMS items to produce a smaller number of latent motivational factors and a twostep cluster analysis was subsequently run using these factors. Two-step cluster analysis undertakes a two-stage process, employing an algorithm similar to k-means clustering, followed by a modified hierarchical procedure. The method offers "the user flexibility to specify the cluster numbers as well as the maximum number of clusters, or to allow the technique to specify the cluster numbers on the basis of statistical evaluation criteria” (Mooi \& Sarstedt, 2011, p. 259). Following generation of the cluster solution, detailed in the Results section, post hoc tests including a series of chi-square tests and oneway analysis of variance (ANOVA) with a Tukey post hoc procedure for group comparisons were run to describe the clusters relative to the questionnaire variables, including items independent of the SEVMS tested for validation purposes.

\section{Results}

Undertaking an initial descriptive analysis of the volunteers sourced from the four events, it was apparent that their profiles were not uniform (Table 1). The volunteers at the Equine WA event were predominantly female (83\%), compared to the majority profile of males at the other three events. This appears to relate to the profile of the sport associated with the event. Competitive sailing has been critiqued as a traditionally masculine sport (Crawley, 1998), while equestrian event participants are predominantly female (British Eventing, 2009). Unlike the other three events at which volunteers were sampled, it appears the Equine WA event attracted volunteers whose skills were transferable from their current or past work roles. Another outlier, in terms of full-time employed volunteers, the Rugby Sevens and Avon Descent events attracted a larger cohort of the fulltime employed, compared to the Equine WA event at which self-employed volunteers dominated, and ISAF at which retirees were heavily represented in the volunteer cohort. The Avon Descent volunteers were also divergent in terms of their higher rate of volunteering for other community organizations. 


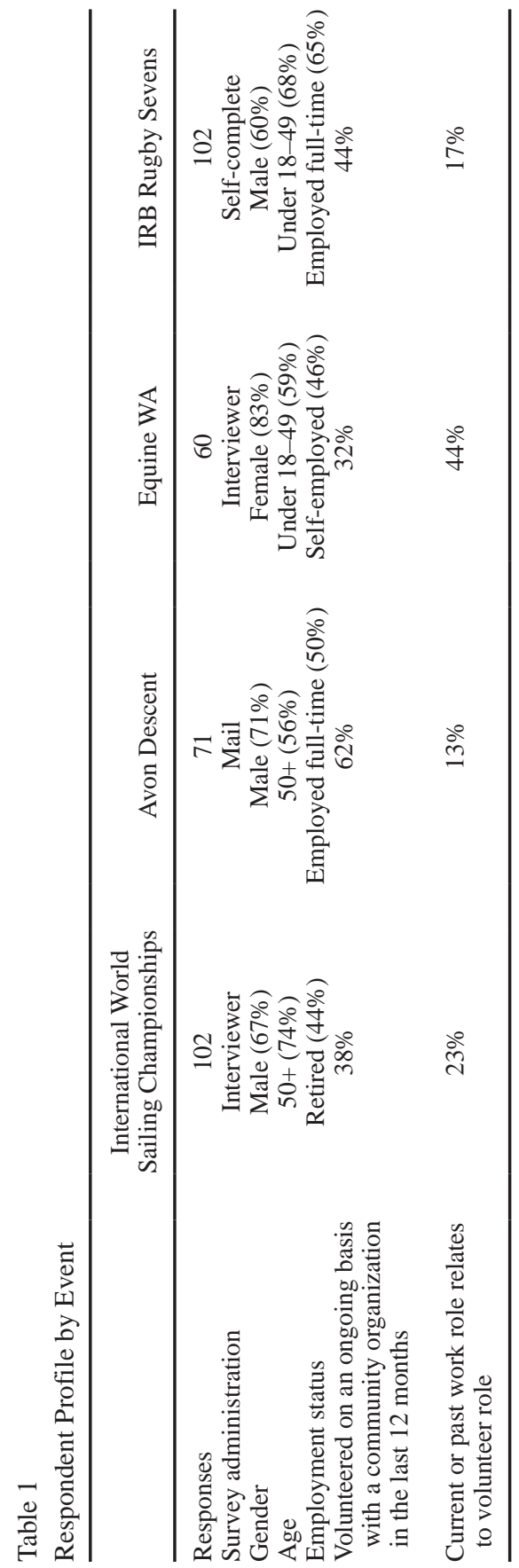

The 28 SEVMS motivation items factored into four motivational factors, a manageable number of constructs, and these were input into the cluster analysis. As noted earlier, several studies (Johnston et al., 1999; Khoo \& Engelhorn, 2007, 2011) have performed such analysis on the SEVMS scale and found a varying number of resulting factors, indicating the scales' factor structure is not constant. Given the intention of the study was to use the resulting factors to form the clusters, not to confirm the structure of the scale and its component factors, EFA was deemed appropriate for current purposes.

Table 2 presents the final results of the EFA analysis, undertaken using Principal Components Analysis with a Varimax rotation. The factor output was evaluated in terms of the Kaiser-Meyer-Olkin (KMO) measure of sampling accuracy. The KMO was 0.861 , which may be considered "meritorious” according to Kaiser's (1974, cited in de Vaus, 2002) interpretation. Three items from the SEVMS were deleted given they failed to load on any factor (I want to interact with others; Volunteering makes me feel better about myself; If I did not volunteer, there would no one to carry out this volunteer work). In total, four factors were extracted with eigenvalues greater than one, accounting for $53 \%$ of the total variance explained. Although this amount is less than desirable, the majority of variance was accounted for and comparable to that explained by the SEVMS in previous studies (Farrell, et al., 1998; Johnston et al., 1999). Table 2 presents the final solution of 25 items with minor cross-loadings removed. All factor loadings are above 0.40 , exceeding the minimum 0.30 level required (Hair, Anderson, Tatham, \& Black, 1998).

In parentheticals next to the items in Table 2 is the assignation of the motivation item based on the four factors from Farrell et al.'s (1998) original SEVMS study. Upon examination of these labels and the resulting factor structure, it was deemed appropriate to name two of the four factors based on the original study, namely, Solidary and Purposive. Acknowledging the Solidary factor contains a mix of items from all four factors of Farrell et al.'s scale, it was nevertheless considered appropriate to label the factor Solidary given the five highest loading items (loadings all above 0.70 ) represented five of the six items of the Solidary factor in the original study. As Hair et al. (1998) note, "variables with higher loadings are 


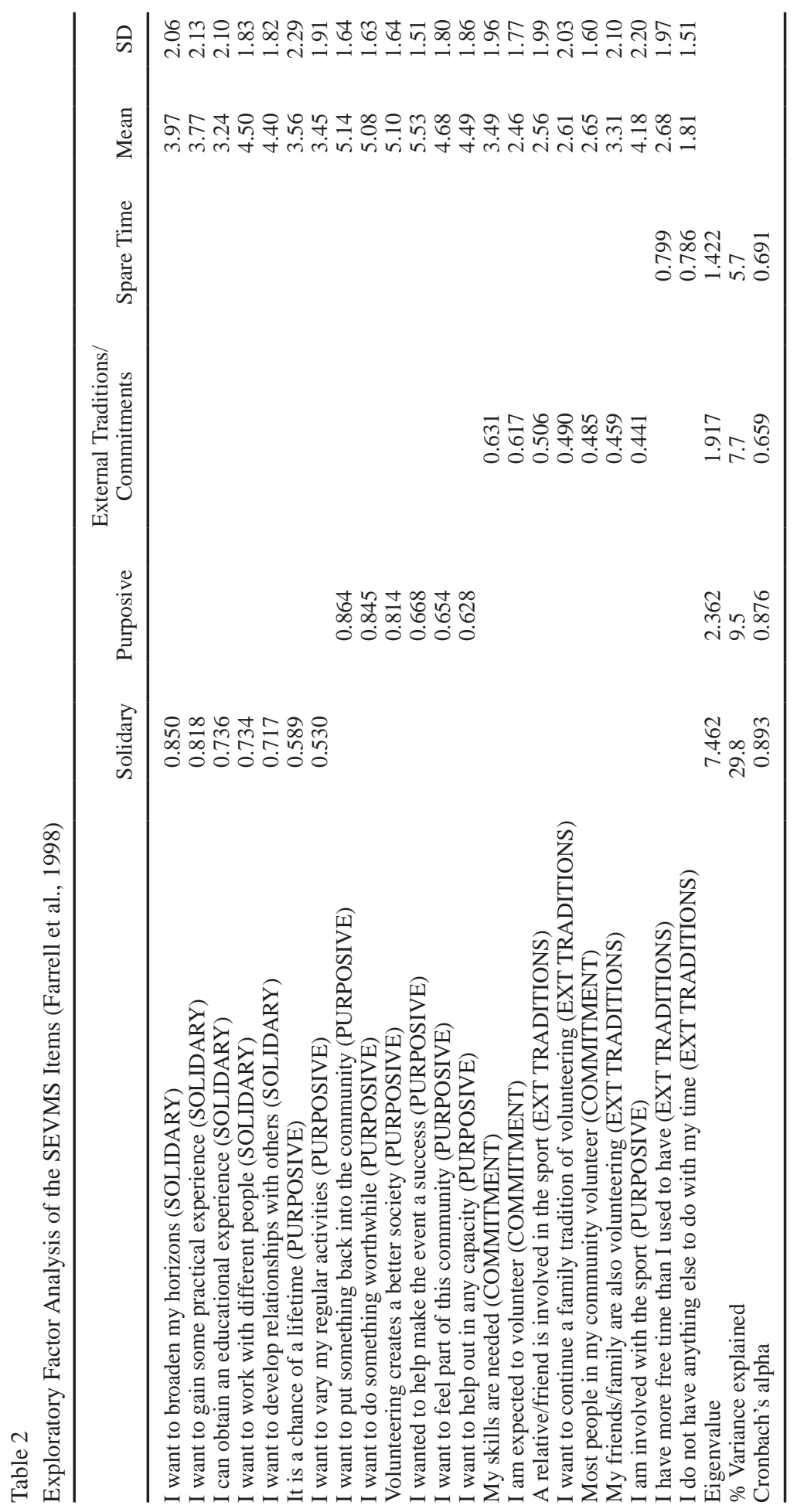


considered more important and have greater influence on the name or label selected to represent a factor" (p. 114). Additionally, two items loading on the current Solidary factor, while loading on different factors in Farrell et al.'s study, have loaded on the Solidary factor in subsequent replications [e.g., the Purposive item "It is a chance of a lifetime" loaded on Twynam et al.'s (2002) and Johnston et al.'s (1999) Solidary factor], while the External Traditions item "I want an opportunity to meet the players and see the event" also loaded on Twynam et al.'s (2002) Solidary factor. Grammatikopoulos et al. (2006) in conducting Confirmatory Factor Analysis on the SEVMS scale items using Greek volunteers noted that previous studies had found the Solidary and Purposive subscales to be distinct motivational dimensions, which in light of their findings, "may represent stable reasons for volunteering, irrespective of cultural context” (p. 301). Like the findings of Johnston et al.'s (1999) study, the items representing External Traditions and Commitments combined on one factor in this study. Upon inspection of the two items loading on Factor 4, while labeled External Traditions in Farrell et al.'s study, both appeared specifically focused on motivations to do with spare time, therefore, the factor was labeled Spare Time accordingly. The Solidary and Purposive factors obtained scores above 0.70 on Cronbach's alpha indicating that the set of items assigned to each were reliable (de Vaus, 2002), with the External Traditions/Commitments and Spare Time factors moderately below this threshold.

Allowing the algorithm to automatically select the appropriate number of clusters based on statistical criteria, the two-step cluster analysis using the motivation factors Solidary, Purposive, External Traditions/Commitments, and Spare Time as input yielded a three-cluster solution, which had a silhouette measure of 0.30, a "fair" solution in terms of quality (Mooi \& Sarstedt, 2011). Prior to finalizing the solution, separate analyses were run using the goodness-of-fit measures Akaike's Information Criterion (AIC) and Bayes Information Criterion (BIC), as AIC as the clustering criteria tends to overestimate the number segments while BIC takes a more conservative approach (Mooi \& Sarstedt, 2011). As Mooi and Sarstedt (2011) contend when such separate analyses are run, it is usually the case that the same results are rendered and this was indeed the case in terms of the current analysis.

A one-way ANOVA was conducted to determine which of the formation factors contributed to differentiating the segments using Euclidean Distance Resemblance Measures (EDRM) as input into interpreting the cluster solution. The results indicated that the Solidary $[F(2,322)=178.803, p=$ $0.000]$, Purposive $[F(2,322)=261.769, p=0.000]$, and Spare Time $[F(2,322)=10.379, p=0.000]$ factors effectively differentiated the clusters, while the External Traditions/Commitment factor did not $[F(2,322)=2.286, p>0.05]$. Table 3 details the means for the clusters on the formation factors, together with the Tukey analyses of homogenous subsets; heterogeneous means are bolded (i.e., where the subset membership is just one cluster) at alpha level 0.05.

As Table 3 indicates, the cluster means on the Solidary and Purposive factors were heterogeneous for all three clusters. For Cluster 3, the Spare Time factor also yielded a distinct subset, while Cluster 1 and 2

Table 3

Cluster Means on Standardized Motivation Factors \& Tukey HSD for Homogenous Subsets

\begin{tabular}{lccc}
\hline Variable & $\begin{array}{c}\text { Cluster 1 } \\
(n=74)\end{array}$ & $\begin{array}{c}\text { Cluster 2 } \\
(n=118)\end{array}$ & $\begin{array}{c}\text { Cluster 3 } \\
(n=143)\end{array}$ \\
\hline Solidary & $\mathbf{- 0 . 9 5 1}$ & -.353 & $\mathbf{0 . 7 8 4}$ \\
Purposive & $\mathbf{0 . 9 4 0}$ & $\mathbf{- 1 . 0 0}$ & $\mathbf{0 . 3 3 9}$ \\
External Traditions/Commitments & -0.211 & 0.090 & 0.035 \\
Spare Time & -0.300 & -0.138 & $\mathbf{0 . 2 6 9}$ \\
\hline
\end{tabular}

Note: Each bolded mean represents a homogenous subset with a cluster membership of one with subset at alpha $=0.05$ and therefore these clusters can be classed as heterogeneous.

Harmonic mean sample size $=103.516$ 
could not be separated (were homogenous) in terms of this factor. Based on this analysis, the clusters were labeled to reflect their distinctive features. Cluster 1, the Altruists, was named in light of its relatively high mean score on the Purposive factor, which reflects "a desire to do something useful and contribute to the community and the event" (Farrell et al., 1998, p. 293). Cluster 3 , the Socials, was named in light of its high score of the Solidary factor, indicating volunteering incentives related to "social interaction, group identification and networking” (Farrell et al., 1998, p. 293). Cluster 2 by comparison had low mean scores for two factors, Solidary and Spare Time, and an extremely low score on the Purposive factor. The only positive for this cluster was External Traditions/ Commitments, with Cluster 2 receiving the highest mean score for this factor (though still a relatively low score) of all the clusters. Examining these factors together, it appears that Cluster 2 volunteers are less motivated by intrinsic reasons for volunteering, rather they seem to be "pushed" to some degree into volunteering by "external influences" (Johnston et al., 1999, p. 168). As such, for present purposes, this cluster was labeled the Indifferents.

Table 4 provides a descriptive profile of the clusters for comparative purposes, using the same variables that were used to profile the respondents by event (detailed in Table 1).

Chi-square analysis revealed no significant differences in the cluster profiles in terms of gender, age, and current or previous work role relating to the event volunteer role. In terms of current employment, the testing [Pearson chi-square $=29.169, d f=$ 8, assymp. significance (two sided) $=0.000$ ] using Adjusted Standardized Residuals (ASR) to assess cells for significantly higher or lower frequencies than expected (Haberman, 1978) indicated that the Indifferents cluster were significantly underrepresented in terms of the full-time employed (ASR = -2.7 ) and retirees (ASR $=-2.2$ ), and overrepresented by the self-employed (ASR = 2.8) and students (ASR = 2.3) based on a critical ASR score of \pm 1.96 (two tailed) using a $p$-value of 0.05 . There were only two other significant differences noted from inspection of the cells: the Socials were significantly underrepresented in terms of the selfemployed category (ASR $=-3.6$ ) and the Altruists were underrepresented in the case of student volunteers (ASR $=-2.2$ ). On the indicator of having volunteered for a community organization during the last 12 months on an ongoing basis [Pearson chi-square $=8.395, d f=2$, assymp. significance (two sided) < 0.05], inspection of the cell frequencies (again based on a critical ASR score of \pm 1.96 , two tailed, using a $p$-value of 0.05 ) revealed that the Altruists were overrepresented in the "yes" response category (ASR $=2.4$ ) and the Indifferents underrepresented (ASR $=-2.4$ ) in response to the same item, indicating their reduced likelihood of having volunteered elsewhere in the recent past.

To assess the criterion validity of the cluster solution, a further one-way ANOVA was run using the satisfaction variables incorporated in the questionnaire. As Mooi and Sarstedt (2011) note, criterion variables should "have a theoretically based relationship with the clustering variables" and "usually relate to managerial outcomes such as . . . satisfaction" (p. 260). Furthermore, they should not be the same variables as those used to form the clusters, as that would represent a tautology (Zanon et al., 2014). The

Table 4

Cluster Profile

\begin{tabular}{|c|c|c|c|}
\hline & Altruists & Indifferents & Socials \\
\hline Number & $\begin{array}{l}74(22 \% \text { of } \\
\text { respondents) }\end{array}$ & 118 (35\% of respondents) & $\begin{array}{l}143 \text { ( } 43 \% \text { of } \\
\text { respondents) }\end{array}$ \\
\hline Gender & Male $(63 \%)$ & Female (51\%) & Male (60\%) \\
\hline Age & $50+(58 \%)$ & Under $18-49$ (54\%) & $50+(52 \%)$ \\
\hline Employment status & $\begin{array}{l}\text { Employed full-time } \\
(46 \%)\end{array}$ & $\begin{array}{l}\text { Employed full-time (32\%); } \\
\text { Self-employed (27\%) }\end{array}$ & $\begin{array}{l}\text { Employed full-time } \\
(48 \%)\end{array}$ \\
\hline $\begin{array}{l}\text { Volunteered on an ongoing basis with a community } \\
\text { organization in the last } 12 \text { months }\end{array}$ & $56 \%$ & $35 \%$ & $45 \%$ \\
\hline Current or past work role relates to volunteer role & $16 \%$ & $31 \%$ & $21 \%$ \\
\hline
\end{tabular}


six items of Brayfield and Rothe's (1951) scale were factor analyzed using Principal Components Analysis and a Varimax rotation. Once again, it was not the intention of the study to confirm the structure of this scale, rather to use the resulting analysis as input into the validation testing, so the use of EFA was deemed appropriate. The resulting solution with a KMO of 0.809 revealed two factors, one containing five items (I feel fairly satisfied with my volunteer role; Most days I am enthusiastic about my volunteer role; I find real enjoyment in my volunteer role; I like my volunteer role better than the average person does; I am seldom bored in my volunteer role) that explained $54 \%$ of the total variance (Cronbach's alpha $=0.845$ ) and a second factor containing one item (I would not consider taking on another kind of volunteer role) that explained $17 \%$ of the variance. The second factor was excluded from further analysis. The results of the ANOVA indicated Factor 1, hereafter named Satisfaction, effectively differentiated the clusters $[F(2$, $322)=68.110, p=0.000$ ] as distinct groups with criterion validity (Mooi \& Sarstedt, 2011).

Table 5 details the means for the clusters on the validation factor, together with the Tukey analyses of homogenous subsets; heterogeneous means at alpha level 0.05 are bolded. The results indicate the Indifferents were in a subset of one, with a significantly different and very low mean score on the Satisfaction factor, compared to the Altruists and Socials, which were grouped together in a homogenous subset.

With clusters formed, interpreted and validated, chi-square analysis was used to examine if there were any differences in the representation of cluster profiles by event type. The results of this analysis [Pearson chi-square $=106.93, d f=6$, assymp. significance (two sided) $=0.000$ ] are detailed in Table 6. Once again, ASR were used assess the cells

Table 5

Cluster Means on Satisfaction Factor \& Tukey HSD for Homogenous Subsets

\begin{tabular}{lccc}
\hline Variable & $\begin{array}{c}\text { Altruists } \\
(n=74)\end{array}$ & $\begin{array}{c}\text { Indifferents } \\
(n=118)\end{array}$ & $\begin{array}{c}\text { Socials } \\
(n=143)\end{array}$ \\
\hline Satisfaction & 0.304 & $\mathbf{- 0 . 7 2 2}$ & 0.483 \\
\hline
\end{tabular}

Note: The bolded mean represents a homogenous subset with a cluster membership of one with subset at alpha $=0.05$ and therefore the cluster can be classed as heterogeneous. Harmonic mean sample size $=103.516$. for significantly higher or lower frequencies than expected. Given the greater number of tests, a critical ASR score of \pm 2.58 (two tailed) was used with a $p$-value of 0.01 to reduce the likelihood of Type II errors. Cells with an ASR score exceeding this threshold are bolded in Table 6 .

Across all events, the analysis indicates the cluster profiles had at least two significantly higher or lower frequencies than expected. Reading vertically down Table 6, the Altruists were underrepresented in the case of the Equine WA event and overrepresented at Avon Descent. The Indifferents were underrepresented at the Sevens and ISAF Sailing events but overrepresented at Equine WA. The profile of the Socials cluster varied for each event, with Socials overrepresented at the Sevens and ISAF events and significantly underrepresented at the Equine WA and Avon Descent events. Overall, Socials were the dominant cluster accounting for $43 \%$ of respondents.

As means of further description of the clusters, four items relating to future volunteering intentions were analyzed using a one-way ANOVA. The results indicated that the items differentiated the clusters in terms of behavioral outcomes, namely:

- I intend to volunteer at the same event in the future $[F(2,265)=7.872, p=0.000]$;

- I intend to start volunteering at another event $[F(2,264)=36.273, p=0.000]$;

- I intend to continue my ongoing volunteering with other organizations $[F(2,318)=47.066, p=$ 0.000]; and

- I intend to start volunteering on an ongoing basis with other organizations $[F(2,317)=69.842, p=$ 0.000].

Table 7 details the means for the clusters on the intention items, together with the Tukey analyses of homogenous subsets. For all items, the findings indicate that based on their intentions, the Indifferents were less likely to volunteer in the future at either the same event or a different one, or continue or start volunteering for another organization. These findings are perhaps not surprising given Tables 3 and 5 respectively highlighted that the Indifferents had less intrinsic motivation to volunteer than the Altruists and Socials and they were also significantly less satisfied with their current 
Table 6

Clusters by Event Type

\begin{tabular}{|c|c|c|c|c|}
\hline \multirow[b]{2}{*}{ Events } & \multicolumn{3}{|c|}{ Clusters } & \multirow[b]{2}{*}{ Total } \\
\hline & Altruists & Indifferents & Socials & \\
\hline \multicolumn{5}{|l|}{ Sevens } \\
\hline Count & 17 & 24 & 61 & 102 \\
\hline$\%$ within event & $16.7 \%$ & $23.5 \%$ & $59.8 \%$ & $100.0 \%$ \\
\hline \% within cluster & $23.0 \%$ & $20.3 \%$ & $42.7 \%$ & $30.4 \%$ \\
\hline Adjusted residual & -1.6 & -3.0 & 4.2 & \\
\hline \multicolumn{5}{|l|}{ ISAF Sailing } \\
\hline Count & 19 & 25 & 58 & 102 \\
\hline \% within event & $18.6 \%$ & $24.5 \%$ & $56.9 \%$ & $100.0 \%$ \\
\hline \% within cluster & $25.7 \%$ & $21.2 \%$ & $40.6 \%$ & $30.4 \%$ \\
\hline Adjusted residual & -1.0 & -2.7 & 3.5 & \\
\hline \multicolumn{5}{|l|}{ Equine WA } \\
\hline Count & 5 & 50 & 5 & 60 \\
\hline$\%$ within event & $8.3 \%$ & $83.3 \%$ & $8.3 \%$ & $100.0 \%$ \\
\hline \% within cluster & $6.8 \%$ & $42.4 \%$ & $3.5 \%$ & $17.9 \%$ \\
\hline Adjusted residual & -2.8 & 8.6 & -5.9 & \\
\hline \multicolumn{5}{|l|}{ Avon Descent } \\
\hline Count & 33 & 19 & 19 & 71 \\
\hline$\%$ within event & $46.5 \%$ & $26.8 \%$ & $26.8 \%$ & $100.0 \%$ \\
\hline \% within cluster & $44.6 \%$ & $16.1 \%$ & $13.3 \%$ & $21.2 \%$ \\
\hline Adjusted residual & 5.6 & -1.7 & -3.1 & \\
\hline \multicolumn{5}{|l|}{ Total } \\
\hline Count & 74 & 118 & 143 & 335 \\
\hline \% within event & $22.1 \%$ & $35.2 \%$ & $42.7 \%$ & $100.0 \%$ \\
\hline \% within cluster & $100.0 \%$ & $100.0 \%$ & $100.0 \%$ & $100.0 \%$ \\
\hline
\end{tabular}

event volunteering experience. These findings would be of potential concern for Equine WA at which the Indifferents were overrepresented in the event's volunteer profile, particularly if the event's organizers are hoping that the current cohort of volunteers will reengage in the future. With greater personal motives for volunteering, the Altruists and Socials were consistently grouped together as a homogenous subset for these four items, with the strongest indications given that these volunteers would volunteer at the same event in the future. This would be of particular benefit to the Avon Descent and Sevens as annual events, respectively overrepresented by Altruists and Socials.

\section{Discussion, Conclusions, and Implications}

The current examination extends the recent studies of Treuren (2014) and Alexander et al.’s (2015) testing the widely replicated SEVMS motivational scale

Table 7

Cluster Means on Intentions Items \& Tukey HSD for Homogenous Subsets

\begin{tabular}{lcccc}
\hline Variable & Altruists & Indifferents & Socials & Harmonic Mean Sample Size \\
\hline I intend to volunteer at the same event in the future & 6.18 & $\mathbf{5 . 1 9}$ & 6.01 & 80.754 \\
I intend to start volunteering at another event & 4.24 & $\mathbf{3 . 2 2}$ & 4.48 & 80.279 \\
I intend to continue my ongoing volunteering with & 4.96 & $\mathbf{3 . 9 5}$ & 5.13 & 99.843 \\
$\quad$ other organizations & & & 4.12 & 99.197 \\
$\quad$ I intend to start volunteering on an ongoing basis & 3.67 & $\mathbf{2 . 6 3}$ & &
\end{tabular}

Note: Each bolded mean represents a homogenous subset with a cluster membership of one with subset at alpha $=0.05$ and therefore these clusters can be classed as heterogeneous.

Items measured on a 7-point Likert scale $(1=$ Strongly Disagree through to $7=$ Strongly Agree $)$. 
(Farrell et al., 1998), based on Cnaan and GoldbergGlen's (1991) generic scale, as a "consistent” scale for the purposes of clustering volunteers sampled from four events. On the basis of this data-driven analysis, three of the four motivational factors, Solidary, Purposive, and Spare Time, effectively differentiated three distinct volunteer clusters.

Examining each cluster in turn, the Altruists had highly purposive motives for volunteering in wishing to help out and give back to the community. This group was smallest of the three clusters discerned; comprising 22\% of the volunteer sample (see Table 6). The Altruists were more likely to already volunteer in their local communities and also indicated strong intentions to continue volunteering at the same event in the future. Although there were no discernible differences between the clusters in terms of their age profile, the Altruists were underrepresented in composition in terms of student volunteers. Examining the cluster by the events sampled, the Altruists were significantly overrepresented and underrepresented at the Avon Descent and Equine WA events, respectively.

The Socials were the largest volunteer cluster. They were homogenously grouped with the Altruists in terms of satisfaction with the current event volunteering experience and future volunteering intentions. Distinctly, the Socials were driven to volunteer by the social, networking, and group outcomes they perceived associated with the experience (e.g., interacting with other volunteers). Unlike the other two clusters, the Socials were a distinct cohort in terms of over or underrepresentation at all four events. In terms of volunteer profile, the Socials were significantly underrepresented in terms of self-employed persons.

The final cluster, though distinct by the very nature of the clustering technique, is perhaps the most contrasting of the three clusters determined. The Indifferents were significantly different and more negative in terms of their solidary and purposive motives for volunteering, the purposive motive in the extreme. Given a lack of internal motives for volunteering, they appear pushed into volunteering by the External Traditions/Commitments factor, suggesting external forces at work behind their decision to volunteer. Although it is beyond the scope of the current study to test causal linkages, it is not unreasonable to assume that this motivational profile explains in part the
Indifferents significantly different and lower ratings in terms of volunteering satisfaction and the future volunteer intention items, akin to the Obligated cluster discerned by Alexander et al. (2015). Additionally, the Indifferents were underrepresented in terms of current volunteering activity. Interestingly, while both the Indifferents and Altruists were homogenous subsets in terms of the Spare Time factor (both indicating a negative mean score), the Altruists were more likely to currently volunteer and indicate their intentions to do so again in the future, suggestive that by comparison, availability was perhaps not the underlying influence curbing the Indifferents volunteering efforts. Indeed, constraints studies have suggested that the barrier "lack of time" can be a proxy for "lack of interest" (Lawton \& Weaver, 2008). The Indifferents made up 35\% of the volunteer sample and were significantly overrepresented at one event in particular, the Equine WA event.

In terms of the management implications of these collective findings, it would appear that event organizers managing the Indifferent cohort would be wasting their resources if investing in strategies to retain them. They may be readily recruited through friends and family, as in the case of the Equine WA event; however, these volunteers did not intend to recommit to volunteering for the event in the future. Management attention and resources instead would be better focused to ensure the Indifferents, without a strong history of prior volunteering, are fully trained and inducted to undertake what might be their once-off volunteering engagement.

For those reoccurring events that are more likely to attract the Altruists (Avon Descent) and Socials (Sevens), retention efforts should focus on continuing to communicate with the volunteers throughout the year, not just in the lead up to the event. However, given the distinct nature of both groups, the appeals should be differently focused with communication to the Altruists reinforcing their contribution to the event as part of helping out in their local community, against highlighting the social and networking aspects of belonging to the event community in the case of the Socials.

Interestingly, the overrepresentation of Socials ( $57 \%$ of their volunteers, see Table 6 ) at the ISAF event presents the organizers of this event with the opportunity to encourage future volunteering with other events of a similar scale and/or nature in the 
host destination as a legacy initiative associated with this globally roaming event. Of course, recruitment and retention decisions by event organizers based on the motivational profiles of their volunteers can only be determined once this information is at hand. As Smith and Lockstone (2009) noted in their study of the selection and screening processes of 12 cultural festivals, screening of volunteers was done on an informal basis with an initial interview serving in most cases as the mechanism for probing the motives of volunteers in order to match them to a suitable role. This level of informality calls in question the capacity and resourcing of event organizers to psychologically screen prospective volunteers. Development of a predictive tool to assist with and inform this process would be a worthwhile applied outcome resulting from further applications of cluster analysis in respect of event volunteerism research.

As noted earlier as background to the current study, the four events sampled employed a mix of traditional and newer event volunteering management models. In his study, Treuren (2014) found that the motivational profile of volunteers varied by recruitment method used (e.g., the socially obligated Conscripts were more likely to be recruited through direct approaches and by friends). It is reasonable to assume in light of this and current evidence, volunteer management models may influence volunteer motivation. Certainly the Indifferents, which were externally pushed into volunteering, were overrepresented at the Equine WA event that employed the BYO model (Lockstone-Binney et al., 2015). They were also more negative in terms of their satisfaction and intentions to volunteer again in the future. This may not be problematic for the organizers based on competitors returning to the event or a new cohort competing as the BYO model assures them of a continued supply of friends and/or family members volunteering. However, such obligated volunteering may have broader implications for the sustainability of the volunteering sector from the perspective of “turning people off” volunteering elsewhere.

In addition, it is interesting to note that both events employing the traditional program management model (ISAF and Sevens) were overrepresented by the Socials cluster. To what extent volunteer management models engender such profiles and outcomes is yet to be empirically determined, as is the ultimate effect of such models on event success. Acknowledging the limitations of the current cross-sectional study, longitudinal research would also be of benefit to track if, and how, antecedent volunteer motivations change as a result of various management interventions (e.g., induction). Future studies might also usefully attempt to collect organizational and volunteer data to test how various volunteer management models directly affect or mediate the relationship between volunteer motives and outcomes, acknowledging that a number of other variables (e.g., sport featured, date and timing of the event, event size, etc.) may confound this relationship.

In answering the question posed at the start of the article, the current findings highlight that not all volunteers engage with events to altruistically help out but rather a mix of motives are at play and these motives can usefully inform the formation of distinct volunteer clusters to which targeted managerial efforts can be directed. With the addition of cluster analyses (Alexander et al., 2015; Treuren, 2014) to the extant literature on event volunteers, a picture of certain common volunteer types attracted or corralled into event volunteering is starting to appear, the exact mix of which is likely to vary at individual events. At the one extreme, despite differences in the motivation scales used to form the clusters and the size and scope of the events under study, a version of the obligated/indifferent volunteer cluster has been discovered by all three recent studies. This common type of volunteer is characterized by a lack of interest in the event at which they are volunteering (Alexander et al., 2015; Treuren, 2014), social obligation compelling them to volunteer (current study; Treuren, 2014), their low levels of satisfaction with the volunteering experience, and reduced intentions to volunteer in the future (current study; Alexander et al., 2015). This collective evidence lends weight to calls (Lockstone-Binney et al., 2014; Strigas \& Jackson, 2003) for future event volunteering motivational research to encompass different settings, types, and scales of events so that over time a fuller understanding of event volunteering motivations and common volunteer types can be revealed.

\section{References}

Agho, A. O., Price, J. L., \& Mueller, C. W. (1992). Discriminant validity of measures of job satisfaction, positive affectivity and negative affectivity. Journal of Occupational and Organizational Psychology, 65, 185-196. 
Alexander, A., Kim, S-B., \& Kim, D-Y. (2015). Segmenting volunteers by motivation in the 2012 London Olympic Games. Tourism Management, 47, 1-10.

Allison, L. D., Okun, M. A., \& Dutridge, K. T. (2002). Assessing volunteer motives: A comparison of an openended probe and Likert rating scales. Journal of Community \& Applied Social Psychology, 12, 243-255.

Australian Government (Department of the Prime Minister and Cabinet). (2011). National volunteering strategy. Canberra: Commonwealth of Australia.

Australian Government (Productivity Commission). (2010). Contribution of the not-for-profit sector. Canberra: Commonwealth of Australia.

Bang, H., Alexandris, K., \& Ross, S. D. (2009). Validation of the revised Volunteer Motivations Scale for International Sporting Events (VMS-ISE) at the Athens 2004 Olympic Games. Event Management, 12, 119-131.

Bang, H., \& Ross, S. (2009). Volunteer motivation and satisfaction. Journal of Venue and Event Management, 1(1), 61-77.

Bang, H., Won, D., \& Kim, Y. (2009). Motivations, commitment, and intentions to continue volunteering for sporting events. Event Management, 13, 69-81.

Brayfield, A. H., \& Rothe, H. F. (1951). An index of job satisfaction. Journal of Applied Psychology, 35, 307-311.

Brayley, N., Obst, P., White, K. M., Lewis, I. M., Warburton, J., \& Spencer, N. M. (2014). Exploring the validity and predictive power of an extended Volunteer Functions Inventory within the context of episodic skilled volunteering by retirees. Journal of Community Psychology, 42(1), 1-18.

British Eventing. (2009). The demographics at a British event for sponsors \& advertisers. Retrieved from http:// www.britisheventing.com/asp-net/page.aspx?section=48 2\&itemTitle=The+Demographics+at+a+British+Event + for + Sponsors+\%26+Advertisers

Caldwell, L. L., \& Andereck, K. L. (1994). Motives for initiating and continuing membership in a recreation-related voluntary association. Leisure Sciences, 16, 33-44.

Clary, E. G., Snyder, M., Ridge, R. D., Copeland, J., Stukas, A. A., Haugen, J., et al. (1998). Understanding and assessing the motivations of volunteers: A functional approach. Journal of Personality and Social Psychology, 74(6), 1516-1530.

Cnaan, R. A., \& Goldberg-Glen, R. S. (1991). Measuring motivation to volunteer in human services. Journal of Applied Behavioural Science, 27, 269-284.

Costa, C., Chalip, L., Green, B., \& Simes, C. (2006). Reconsidering the role of training in event volunteers' satisfaction. Sport Management Review, 9, 165-182.

Coyne, B. S., \& Coyne, E. J. (2001). Getting, keeping and caring for unpaid volunteers for professional golf tournament events. Human Resource Development International, 4(2), 199-214.

Cravens, D. W., \& Piercy, N. F. (2006). Strategic marketing (8th ed.). Singapore: McGraw-Hill Education.

Crawley, S. (1998). Gender, class and the construction of masculinity in professional sailing. International Review for the Sociology of Sport, 33(1), 33-42.
Cuskelly, G., Auld, C., Harrington, M., \& Coleman, D. (2004). Predicting the behavioural dependability of sport event volunteers. Event Management, 9, 73-89.

Cuskelly, G., Hoye, R., \& Auld, C. (2006). Working with volunteers in sport: Theory and practice. London: Routledge.

de Vaus, D. A. (2002). Analyzing social science data. London: Sage.

Dolnicar, S., \& Randle, M. (2007a). The international volunteering market: Market segments and competitive relations. International Journal of Nonprofit and Voluntary Sector Marketing, 12, 350-370.

Dolnicar, S., \& Randle, M. (2007b). What motivates which volunteers? Psychographic heterogeneity among volunteers in Australia. Voluntas, 18, 135-155.

Dickson, T. J., Benson, A. M., Blackman, D. A., \& Terwiel, A. F. (2013). It's all about the Games! 2010 Vancouver Olympic and Paralympic Winter Games volunteers. Event Management, 17, 77-92.

Farrell, J., Johnston, M., \& Twynam, D. (1998). Volunteer motivation, satisfaction and management and an elite sporting competition. Journal of Sport Management, 12, 288-300.

Finkelstein, M. (2008). Volunteer satisfaction and volunteer action: A functional approach. Social Behavior and Personality, 36(1), 9-18.

Gaskin, K. (2003). A choice blend: What volunteers want from organisation and management. London: Institute for Volunteer Research.

Giannoulakis, C., Wang, C-H., \& Gray, D. (2008). Measuring volunteer motivation in mega-sporting events. Event Management, 11, 191-200.

Grammatikopoulos, V., Koustelios, A., \& Tsigilis, N. (2006). Construct validity of the Special Event Volunteer Motivation Scale for Greek volunteers. Leisure/Loisir, 30(1), 287-305.

Grimm, R., Dietz, N., Foster-Bey, J., Reingold, D., \& Nesbit, R. (2006). Volunteer growth in America: A review of trends since 1974. Washington, DC: Corporation for National \& Community Service.

Haberman, S. J. (1978). Analysis of qualitative data, Volume 1, introductory topics. New York: Academic Press Inc.

Hair, J. F., Anderson, R. E., Tatham, R. L., \& Black, W. C. (1998). Multivariate data analysis (5th ed.). Upper Saddle River, NJ: Prentice-Hall.

Holmes, K., \& Smith, K. A. (2009). Managing volunteers in tourism: Attractions, destinations and events. Oxford: Elsevier.

Hustinx, L., \& Lammertyn, F. (2004). The cultural bases of volunteering: Understanding and predicting attitudinal differences between Flemish Red Cross volunteers. Nonprofit and Voluntary Sector Quarterly, 33(4), 548-584.

International Olympic Committee. (2012). Olympic legacy. Lausanne, Switzerland: Author.

Iverson, R. D. (1996). Employee acceptance of organizational change: The role of organizational commitment. The International Journal of Human Resources Management, 7(1), 122-149. 
Johnston, M., Twynam, D., \& Farrell, J. (1999). Motivation and satisfaction of event volunteers for a major youth organization. Leisure/Loisir, 24(1/2), 161-177.

Kaiser, H. F. (1974). An index of factorial simplicity. Psychometrica, 39, 31-36.

Kemp, S. (2002). The hidden workforce: Volunteers' learning in the Olympics. Journal of European Industrial Training, 26(2), 109-116.

Khoo, S., \& Engelhorn, R. (2007). Volunteer motivations for the Malaysian Paralympiad. Tourism and Hospitality Planning \& Development, 4(3), 159-167.

Khoo, S., \& Engelhorn, R. (2011). Volunteer motivations at a national special Olympics event. Adapted Physical Activity Quarterly, 28, 27-39.

Lai, M. H. C., Ren, M. Y. W., Wu, A. M. S., \& Hung, E. P. W. (2013). Motivation as mediator between national identity and intention to volunteer. Journal of Community \& Applied Social Psychology, 23, 128-142.

Lawton, L. J., \& Weaver, D. B. (2008). Factors associated with non-visitation by area to Congaree National Park, South Carolina. Journal of Park and Recreation Administration, 26(4), 66-82.

Lockstone, L., Smith, K., \& Baum, T. (2010). Volunteering flexibility across the tourism sector. Managing Leisure, 15(1), 111-127.

Lockstone-Binney, L., Holmes, K., Baum, T., \& Smith, K. (2014). Event volunteering evaluation (EVE) project: Challenging the methodological limits of event volunteering research. In K. A. Smith, L. Lockstone-Binney, K. Holmes, \& T. Baum (Eds.), Event volunteering: International perspectives on the event volunteering experience (pp. 167-181). Abingdon, Oxford: Routledge.

Lockstone-Binney, L., Smith, K., Holmes, K., \& Baum, T. (2015). Exploring future forms of event volunteering. In I. Yeoman, M. Robertson, U. McMahon-Beattie, E. Backer, \& K. Smith (Eds.), The future of events \& festivals (pp. 175-186). Abingdon, Oxford: Routledge.

Macduff, N. (1991). Episodic volunteering: Building the short-term volunteer program. Walla Walla, WA: MBA Publishing.

MacLean, J., \& Hamm, S. (2007). Motivation, commitment and intention of volunteers at a large Canadian sporting event. Leisure/Loisir, 31(2), 523-556.

Meijs, L., \& Hoogstad, E. (2001). New ways of managing volunteers: Combining membership management and programme management. Voluntary Action, 3(3), 41-61.

Merrill, M. V. (2006). Global trends and the challenges for volunteering. The International Journal of Volunteer Administration, XXIV(1), 9-14.

Monga, M. (2006). Measuring motivation to volunteer for special events. Event Management, 10, 47-61.

Mooi, E., \& Sarstedt, M. (2011). A concise guide to market research. Berlin, Germany: Springer.

Omoto, A. M., \& Snyder, M. (1995). Sustained helping without obligation: Motivation, longevity of service and perceived attitude change among AIDS volunteers. Journal of Personality and Social Psychology, 68(4), 671-686.
Okun, M. A., Barr, A., \& Herzog, A. R. (1998). Motivation to volunteer by older adults: A test of competing measurement models. Psychology and Aging, 13, 608-621.

Okun, M. A., \& Schultz, A. (2003). Age and motives for volunteering: Testing hypotheses derived from socioemotional selectivity theory. Psychology and Aging, 18(2), 231-239.

Palmer, R. A., \& Millier, P. (2004). Segmentation: Identification, intuition, and implementation. Industrial Marketing Management, 33(8), 779-785.

Pauline, G., \& Pauline, J. (2009). Volunteer motivation and demographic influences at a professional tennis event. Team Performance Management, 15(3/4), 172-184.

Penner, L. A., \& Finkelstein, M. A. (1998). Dispositional and structural determinants of volunteerism. Journal of Personality and Social Psychology, 74(2) 525-537.

Price, J. L., \& Mueller, C. W. (1986). Absenteeism and turnover of hospital employees. Greenwich, CT: JAI Press.

Randle, M., \& Dolnicar, S. (2009). Not just any volunteers: Segmenting the market to attract the high contributors. Journal of Nonprofit \& Public Sector Marketing, 21, 271-282.

Reeser, J. C., Berg, R. L., Rhea, D., \& Willick, S. (2005). Motivation and satisfaction among polyclinic volunteers at the 2002 Winter Olympic and Paralympic Games. British Journal of Sports Medicine, 39, 1-5.

Rochester, C., Ellis Paine, A., \& Howlett, S. (2009). Volunteering and society in the 21st century. Basingstoke, UK: Palgrave Macmillan.

Saleh, F., \& Wood, C. (1998). Motives of volunteers in multicultural festivals: The case of Saskatoon Folkfest. Festival Management \& Event Tourism, 5(1/2), 59-70.

Smith, K. A., \& Lockstone, L. (2009). Involving and keeping event volunteers: Management insights from cultural festivals. In T. Baum, M. Deery, C. Hanlon, L. Lockstone, \& K. Smith (Eds.), People and work in events and conventions: A research perspective (pp. 154-167). Wallingford, UK: CABI International.

Strigas, A., \& Jackson, N. (2003). Motivating volunteers to serve and succeed: Design and results of a pilot study that explores demographics and motivational factors in sport volunteerism. International Sports Journal, 7(1), 111-121.

Treuren, G. (2009). The associative-supportive motivation as a factor in the decision to event volunteer. Leisure/ Loisir, 33(2), 687-711.

Treuren, G. J. M. (2014). Enthusiasts, conscripts or instrumentalists? The motivational profiles of event volunteers. Managing Leisure, 19(1), 51-70.

Twynam, D., Farrell, J., \& Johnston, M. (2002). Leisure and volunteer motivation at a special sporting event. Leisure/ Loisir, 27(3/4), 363-377.

Wollebaek, D., Skirstad, B., \& Handstad, D. (2014). Between two volunteers cultures: Social composition and motivation at the 2010 test event for the FIS Nordic World Ski Championships. International Review of Sociology of Sport, 49(1), 22-41. 
Wymer, W. W. (1997). Segmenting volunteers using values, self-esteem, empathy, and facilitation as determinant variables. Journal of Nonprofit \& Public Sector Marketing, 5(2), 3-28.

Wymer, W. W., \& Starnes, B. J. (1999). Segmenting subgroups of volunteers for target marketing: Differentiating traditional hospice volunteers from other volunteers.
Journal of Nonprofit \& Public Sector Marketing, 6(2-3), 25-50.

Zanon, D., Hall, J., Lockstone-Binney, L., \& Weber, D. (2014). Development of a whole agency approach to market segmentation in parks. Journal of Leisure Research, 46(5), 563-592. 